Sônia Regina Panzarini ${ }^{(b)}$

Denise Pedrini(a)

Wilson Roberto Poi(b)

Celso Koogi Sonoda(b)

Daniela Atili Brandini $i^{(a)}$

José Carlos Monteiro de Castro(a)

(a) PhDs, Assistant Professors; (b)PhDs, Adjunct Professors - Department of Surgery and Integrated Clinic, School of Dentistry of

Araçatuba, São Paulo State University

(UNESP), Araçatuba, SP, Brazil.

\section{Dental trauma involving root fracture and periodontal ligament injury: a 10-year retrospective study}

\begin{abstract}
The purpose of this retrospective study was to analyze the cases of traumatic dental injuries involving root fracture and/or periodontal ligament injury (except avulsion) treated at the Discipline of Integrated Clinic, School of Dentistry of Araçatuba, São Paulo State University (UNESP), Brazil, from January 1992 to December 2002. Clinical and radiographic records from 161 patients with 287 traumatized teeth that had sustained root fracture and/or injuries to the periodontal ligament were examined. The results of this survey revealed that subluxation $(25.09 \%)$ was the most common type of periodontal ligament injury, followed by extrusive luxation $(19.86 \%)$. There was a predominance of young male patients and most of them did not present systemic alterations. Among the etiologic factors, the most frequent causes were falls and bicycle accidents. Injuries on extraoral soft tissues were mostly laceration and abrasion, while gingival and lip mucosa lacerations prevailed on intraoral soft tissues injuries. Radiographically, the most common finding was an increase of the periodontal ligament space. The most commonly performed treatment was root canal therapy. Within the limits of this study, it can be concluded that traumatic dental injuries occur more frequently in young male individuals, due to falls and bicycle accidents. Subluxation was the most common type of periodontal ligament injury. Root canal therapy was the type of treatment most commonly planned and performed.
\end{abstract}

Descriptors: Tooth injuries; Periodontal ligament; Comprehensive dental care; Soft tissue injuries; Facial injuries.
Corresponding author:

Sônia Regina Panzarini

Departamento de Cirurgia e Clínica

Integrada

Disciplina de Clínica Integrada

Faculdade de Odontologia do Campus

de Araçatuba (UNESP)

Rua José Bonifácio, 1193

Araçatuba - SP - Brazil

CEP: 16015-050

E-mail: panzarin@foa.unesp.br

Received for publication on Mar 01, 2007

Accepted for publication on Jun 20, 2007 


\section{Introduction}

Current Dentistry presents high scientific and technological standards, and, in most cases, it is capable of reestablishing esthetics and function to patients. Nevertheless, traumatic dental injuries are still a great challenge inasmuch as they usually injure teeth and their supporting tissues in a precocious phase and frequently with an unfavorable prognosis that can lead to tooth loss.

Statistical data underscore the magnitude of this problem and indicate that one out of ten individuals had sustained dental trauma during childhood or adolescence. These data also highlight that some conditions, such as an increased incisal overjet and resulting inadequate lip coverage, are important predisposing factors to be considered. ${ }^{1-4}$

Dental traumatisms may be classified according to several factors. Andreasen's ${ }^{1}$ classification is based on the classification proposed by the World Health Organization (WHO) in 1992 and can be applied for both primary and permanent dentitions.

Regarding occurrence and etiology, it is observed that traumatic dental injuries are less common during the first years of childhood. Occurrence increases when the child starts walking alone due to his/her lack of experience and coordination in movements. This occurrence reaches its apex during school years, mainly as a result of falls..$^{2-10}$

During adolescence, most of the traumatic dental injuries are attributable to accidents in sports activities. Some authors have described that approximately $1.5 \%$ to $3.5 \%$ of all adolescents practicing sports activities undergo traumatic dental injuries annually. In late adolescence and early adulthood, these injuries associated to automotive accidents are prevalent. ${ }^{11}$

Traumatic dental injuries related to fights are usually more common in older individuals. Other groups that present high incidences of traumatisms in the orofacial region are epileptics, alcoholics and drug users. ${ }^{1,12}$

Knowledge of the different factors related to dental trauma, such as its etiology and types of treatment, is essential for a better understanding of the biological mechanisms involved in wound healing. Therefore, it allows a better selection of therapeutic measures. ${ }^{13-15}$
The purpose of this retrospective study was to analyze the cases of traumatic dental injuries involving root fracture and periodontal ligament injury (except avulsion) treated at the Discipline of Integrated Clinic, School of Dentistry of Araçatuba, São Paulo State University (UNESP), during a 10 -year period.

\section{Material and Methods}

Clinical and radiographic records of 161 young and adult patients with 287 traumatized teeth in the permanent dentition were examined. The patients had been treated at the Discipline of Integrated Clinic, School of Dentistry of Araçatuba (UNESP), Brazil, from January 1992 to December 2002. Only cases of trauma involving root fracture and/or injuries to the periodontal ligament (except avulsion), according to Andreasen's ${ }^{1}$ classification, were included in this survey.

Data were compiled from the case report forms used at the Discipline of Integrated Clinic. The following information was available: identification of the patient, medical history, former and current history of dental trauma, extraoral and intraoral physical examination including both soft and hard tissues, radiographic findings, diagnosis based on Andreasen's ${ }^{1}$ classification and treatment plan as well as the treatment currently performed.

\section{Results}

From 1992 to 2002, 346 patients with traumatic dental injuries were referred for treatment at the Discipline of Integrated Clinic, School of Dentistry of Araçatuba. Of these 346 patients, 161 had sustained a trauma involving root fracture and/or periodontal ligament injury in 287 teeth, which were the scope of this survey.

Review of the records showed a predominance of male patients, most of them belonging to the 12-18 year-old group.

In response to the medical history item, 64 patients $(40 \%)$ reported no systemic alterations and 57 (35\%) left this item blank. Among the 40 patients $(25 \%)$ who reported any systemic problem, the alterations mentioned were: allergic reaction to drugs (6), controlled hypertension (4), epilepsy (2), bron- 
chitis (7), frequent tonsillitis (2), adenoids (1), pneumonia (1), mycosis (1), anemia (1), type A hepatitis (1), cardiac surgery (1), nervousness (1), allergic reaction to other substances (4), asthma (1), Hansen's disease (1), depression (2), HIV positive (1), convulsion (1), diabetes (1) and rheumatism (1).

From the 161 case report forms evaluated, 12 $(7.5 \%)$ mentioned previous traumatic dental injuries.

The most frequently reported accident site was the street, corresponding to 91 cases $(57 \%)$, followed by 23 cases of home accidents $(14 \%)$. Other $39(25 \%)$ sites were distributed among clubs (10), schools (7), highways (5), outskirts (8), soccer fields (2), parks (1), gyms (1), working places (4) and gas stations (1). In 8 case report forms (5\%), this information was missing.

Direct impact was the type of trauma that resulted in the largest number of traumatic dental injuries (133, corresponding to $82.60 \%$ of the cases), while indirect impact was the cause of injury in only 3 patients $(1.86 \%)$. In 25 forms (16\%), this information was missing. The etiologic factors responsible for the traumatisms in the surveyed population were bicycle accidents (42), falls (42), motorcycle accidents (28), car accidents (13), aggressions (13), sports (8), work accidents (4), collisions (4) and epilepsy episodes (1). In 6 case report forms, this information was missing.

Regarding the first-aid sites, 67 patients were taken to hospitals and emergency rooms (42\%), 19 were first treated at private dental offices $(12 \%)$ and 14 were directly referred to the School of Dentistry of Araçatuba (9\%). However, in a large number of forms $(61$, corresponding to $37 \%$ of the cases), this information was not available. The procedures performed at first-aid care included suture (37), dental splint therapy (36), pulp capping (1), tooth repositioning (16), tooth extraction (4) and pulpectomy (2). In 65 case report forms, this information was missing. The most frequently administered medications were antibiotics (55), anti-inflammatories (43), analgesics (18), antitetanic vaccines (13) and mouthwashes (2). In 4 cases, no drugs were administered and in 84 case report forms this item was left blank.

The findings from intraoral and extraoral examinations are summarized in Tables 1 and 2 .

Complementary tests performed for diagnosis included 166 percussion tests, 20 heat sensitivity tests, 60 cold sensitivity tests, 29 occlusal exams and 2 mobility assessments.

Table 1 - Types of extraoral injuries (Andreasen's classification).

\begin{tabular}{|c|c|c|c|c|c|}
\hline \multirow{2}{*}{ Injury } & \multicolumn{4}{|c|}{ Site } & \multirow{2}{*}{ Total $(n=161)$} \\
\hline & Face & Lip & Mentum & Nose & \\
\hline Laceration & $6(3.7 \%)$ & 28 (17.4\%) & 7 (4.3\%) & 0 & 41 (25.4\%) \\
\hline Abrasion & $14(8.7 \%)$ & $9 \quad(5.6 \%)$ & $6(3.7 \%)$ & $4(2.5 \%)$ & $33(20.7 \%)$ \\
\hline Contusion & $10(6.2 \%)$ & 18 (11.1\%) & $3(1.8 \%)$ & $3(1.8 \%)$ & $34(21 \%)$ \\
\hline No injury & - & - & - & - & $02 \quad(1.2 \%)$ \\
\hline No answer & - & - & - & - & 51 (31.7\%) \\
\hline
\end{tabular}

Table 2 - Types of intraoral injuries (Andreasen's classification)

\begin{tabular}{|c|c|c|c|c|c|c|}
\hline \multirow[b]{2}{*}{ Injury } & \multicolumn{5}{|c|}{ Site } & \multirow{2}{*}{$\begin{array}{c}\text { Total } \\
(\mathrm{n}=161)\end{array}$} \\
\hline & Lip mucosa & Gingiva & $\begin{array}{l}\text { Alveolar } \\
\text { mucosa }\end{array}$ & $\begin{array}{l}\text { Cheek } \\
\text { Mucosa }\end{array}$ & Tongue & \\
\hline Laceration & 29 (18\%) & $28(17.4 \%)$ & 3 (1.8\%) & $2(1.2 \%)$ & 2 (1.2\%) & 64 (39.6\%) \\
\hline Abrasion & 3 (1.8\%) & $1 \quad(0.6 \%)$ & 0 & 0 & 0 & $4 \quad(2.4 \%)$ \\
\hline Contusion & $9 \quad(5.6 \%)$ & 18 (1 1.1\%) & 1 (0.6\%) & $2(1.2 \%)$ & 0 & 30 (18.5\%) \\
\hline No injury & - & - & - & - & - & $5 \quad(3.1 \%)$ \\
\hline No answer & - & - & - & - & - & 58 (36.4\%) \\
\hline
\end{tabular}


Radiographic findings obtained from the patients' case report forms are presented in Table 3.

Data regarding to periodontal ligament injuries (except avulsion) and root fracture for both maxillary and mandibular arches are shown in Tables 4 and 5.

The treatment plans varied according to the type of dental traumatism. Treatment plans re-

Table 3 - Radiographic findings.

\begin{tabular}{l|r|r}
\hline \multicolumn{1}{|c|}{ Finding } & $\begin{array}{r}\text { Number } \\
\text { of cases }\end{array}$ & \multicolumn{1}{c}{$\%$} \\
\hline Thickening of the periodontal ligament space & 34 & 11.8 \\
\hline $\begin{array}{l}\text { Increase of the periodontal ligament space } \\
\text { - tooth dislodgment }\end{array}$ & 40 & 13.9 \\
\hline Root fracture - cervical third & 1 & 0.3 \\
\hline Root fracture - middle third & 25 & 8.7 \\
\hline Root fracture - apical third & 5 & 1.7 \\
\hline Fracture of the alveolar process & 8 & 2.7 \\
\hline Bone loss & 3 & 1.0 \\
\hline External root resorption & 10 & 3.4 \\
\hline Internal root resorption & 3 & 1.0 \\
\hline Tooth dislodgement & 3 & 1.0 \\
\hline Root canal obliteration & 3 & 1.0 \\
\hline Periapical radiolucent area & 11 & 3.8 \\
\hline Crown fracture & 10 & 3.4 \\
\hline Absence of periodontal ligament space & 4 & 1.3 \\
\hline Maxillary or mandibular fracture & 1 & 0.3 \\
\hline Empty alveolus & 3 & 1.0 \\
\hline No visible alteration & 123 & 42.8 \\
\hline Total & & 100 \\
\hline
\end{tabular}

Table 4 - Classification and incidence of periodontal ligament injuries and root fractures in the maxillary arch (Andreasen's ${ }^{1}$ classification).

\begin{tabular}{l|r|r|r|r|r|c}
\hline \multirow{2}{*}{\multicolumn{1}{c|}{ Classification }} & \multicolumn{6}{|c}{ Tooth } \\
\cline { 2 - 8 } & 13 & 12 & 11 & 21 & 22 & 23 \\
\hline Root fracture $(\mathrm{n}=32)$ & 1 & 1 & 17 & 11 & 2 & - \\
\hline Concussion $(\mathrm{n}=31)$ & 2 & 3 & 13 & 7 & 5 & 1 \\
\hline Subluxation $(\mathrm{n}=63)$ & - & 17 & 23 & 14 & 7 & 2 \\
\hline Extrusive luxation $(\mathrm{n}=41)$ & 1 & 6 & 15 & 12 & 7 & - \\
\hline Lateral luxation $(\mathrm{n}=34)$ & - & 4 & 12 & 12 & 4 & 2 \\
\hline Intrusion $(\mathrm{n}=24)$ & 2 & 1 & 7 & 10 & 4 & - \\
\hline Total $(\mathrm{n}=225)$ & 6 & 32 & 87 & 66 & 29 & 5 \\
\hline
\end{tabular}

ported were root canal therapy $(40 \%)$, dental splint therapy $(17 \%)$, surveillance $(14 \%)$, composite resin restoration $(10 \%)$, tooth repositioning $(7 \%)$, tooth extraction $(6 \%)$ and others $(6 \%)$. Treatments actually performed were root canal therapy $(6 \%)$, dental splint therapy $(15 \%)$, surveillance $(12 \%)$, composite resin restoration $(7 \%)$, tooth repositioning $(6 \%)$, tooth extraction $(6 \%)$, intracanal calcium hydroxide dressing changes $(41 \%)$, occlusal adjustment $(2 \%)$, temporary partial prosthesis $(2 \%)$ and others $(3 \%)$.

\section{Discussion}

The great convenience of such a retrospective study is that it gives an overview of the traumatic dental injuries with respect to the profile of the most affected patients, the etiologic factors involved and the most frequently adopted treatment plans. Putting the information all together leads to a better knowledge of the different types of injuries. It also allows the choice of the most effective and long-lasting therapeutic procedures. . $^{3,4,10-16}$

The Discipline of Integrated Clinic of the School of Dentistry of Araçatuba has a clinical service for patients who have suffered traumatic dental injuries. The patients are treated by a fourth-year dental student and a graduate student from the Oral and Maxillofacial Surgery course together. This multidisciplinary approach is essential for the treatment of traumatic dental injuries.

In this study, the finding of a greater frequency of traumatic dental injuries in 12-18 year-old male

Table 5 - Classification and incidence of periodontal ligament injuries and root fractures in the mandibular arch (Andreasen's classification).

\begin{tabular}{l|c|c|r|r|r|c}
\hline \multirow{2}{*}{\multicolumn{1}{c|}{ Classification }} & \multicolumn{7}{c}{ Tooth } \\
\cline { 2 - 8 } & 33 & 32 & 31 & 41 & 42 & 43 \\
\hline Root fracture $(\mathrm{n}=10)$ & 2 & 2 & 2 & 2 & 2 & - \\
\hline Concussion $(\mathrm{n}=17)$ & - & 3 & 4 & 5 & 3 & 2 \\
\hline Subluxation $(\mathrm{n}=9)$ & 1 & 2 & 3 & 2 & 1 & - \\
\hline Extrusive luxation $(\mathrm{n}=16)$ & - & 1 & 5 & 6 & 4 & - \\
\hline Lateral luxation $(\mathrm{n}=10)$ & - & 1 & 2 & 4 & 3 & - \\
\hline Intrusion $(\mathrm{n}=0)$ & - & - & - & - & - & - \\
\hline Total $(\mathrm{n}=62)$ & 3 & 9 & 16 & 19 & 13 & 2 \\
\hline
\end{tabular}


patients is supported by the majority of the previous studies. $^{1-4,6-11,16-18}$

The first and foremost steps in treating a traumatized patient should be physical examination and medical history review. Data obtained from this survey showed that $40 \%$ of the patients denied systemic alterations, which is consistent with their mean age.

Regarding etiology, falls and bicycle accidents were the most common causes of traumatisms, which is in agreement with the findings of previous studies. ${ }^{2-10}$

Laceration was the most common extraoral injury. This is easily explained since most of the traumas were caused by direct impacts, in which lips act as a shield. ${ }^{1}$ Intraoral examinations revealed that gingival and lip laceration were the most common soft tissue injuries due to tooth dislodgement, mainly in cases of luxation. ${ }^{1}$

Among the complementary tests, percussion and thermal sensitivity tests were largely performed to obtain information regarding damage to periodontal ligament and pulp tissue, respectively. ${ }^{1,15,19}$ Pulp sensitivity tests require the patient's cooperation, which is frequently not achieved during first-aid care. Therefore, the validity of these tests is controversial. Andreasen ${ }^{19}$ (1989) postulated that sensitivity responses may be temporarily reduced, especially in traumatic luxations. Consequently, sensitivity tests should be postponed to a subsequent visit.

All traumatized teeth should be radiographed to investigate the existence of root fracture and/or injuries to periodontal structures as well as to assess root development stage. These are important factors accounting for the establishment of the treatment plan. ${ }^{1,15}$

Following Andreasen's ${ }^{1}$ classification, 72 out of 287 teeth involved in this study had subluxation. This finding is in agreement with the patients' age, type of impact (direct) and soft tissue injuries (lip lacerations).

The therapeutic approach for traumatic dental injuries varies according to the dentition affected (primary or permanent) and to the type of damage for both the teeth and supporting structures. ${ }^{1,15,18}$ In this context, it should be kept in mind that the treatment plan must be carefully elaborated. This would avoid new traumas that would worsen the prognosis, which is not so favorable in many cases.

Root canal therapy is advised mainly for luxations (extrusive, lateral and intrusive) in which pulp neurovascular supply is disrupted. This would avoid pulp necrosis leading to external inflammatory root resorption. ${ }^{1,14,15,19-21}$ Intracanal calcium hydroxide dressing placement and changes are widely employed procedures due to the well-recognized anti-bacterial and healing properties of calcium hydroxide. ${ }^{22}$ It also has the ability of preventing and/or arresting the process in cases of ongoing external inflammatory root resorption. ${ }^{21,22}$

Occlusal adjustment is another key step of the treatment plan because tooth repositioning does not necessarily return it to its original position. Even small dislodgements may provide premature contacts that cause undesirable additional traumas. ${ }^{1}$

Follow-up of any type of traumatism is of paramount importance because it is not possible to know exactly the extent of damage for both the tooth and the supporting tissues or predict future consequences. ${ }^{1}$ However, this is difficult to be achieved since it depends on the patient's compliance on a long-term basis.

Management of traumatic dental injuries usually requires a multidisciplinary approach for long periods of time. Therefore, general dentists should be prepared to treat properly the cases of dental injuries since they are the professionals more likely to face them in clinical practice.

\section{Conclusion}

Within the limits of this study, it can be concluded that traumatic dental injuries occur more frequently in young male individuals, due to falls and bicycle accidents. Subluxation was the most common type of periodontal ligament injury. Root canal therapy was the type of treatment most commonly planned and performed. 


\section{References}

1. Andreasen JO, Andreasen FM. Textbook and color atlas of traumatic injuries to the teeth. Copenhagen: Munksgaard; 1994.

2. Artun J, Behbehani F, Al-Jame B, Kerosuo H. Incisor trauma in an adolescent Arab population: prevalence, severity, and occlusal risk factors. Am J Orthod Dentofacial Orthop. 2005;128(3):347-52.

3. Malikaew P, Watt RG, Sheiham A. Prevalence and factors associated with traumatic dental injuries (TDI) to anterior teeth of 11-13 year old Thai children. Community Dent Health. 2006;23(4):222-7.

4. Traebert J, Bittencourt DD, Peres KG, Peres MA, de Lacerda JT, Marcenes W. Aetiology and rates of treatment of traumatic dental injuries among 12-year-old school children in a town in southern Brazil. Dent Traumatol. 2006;22(4):173-8.

5. Kirzioglu Z, Karayilmaz H, Erturk MS, Koseler Sentut T. Epidemiology of traumatised primary teeth in the west-Mediterranean region of Turkey. Int Dent J. 2005;55(5):329-33.

6. Lang B, Pohl Y, Filippi A. Knowledge and prevention of dental trauma in team handball in Switzerland and Germany. Dent Traumatol. 2002;18(6):329-34.

7. Majorana A, Bardellini E, Conti G, Keller E, Pasini S. Root resorption in dental trauma: 45 cases followed for 5 years. Dent Traumatol. 2003;19(5):262-5.

8. Saroglu I, Sönmez H. The prevalence of traumatic injuries treated in the pedodontic clinic of Ankara University, Turkey, during 18 months. Dent Traumatol. 2002;18(6):299-303.

9. Sandalli N, Cildir S, Guler N. Clinical investigation of traumatic injuries in Yeditepe University, Turkey during the last 3 years. Dent Traumatol. 2005;21(4):188-94.

10. Traebert J, Peres MA, Blank V, Boell RS, Pietruza JA. Prevalence of traumatic dental injury and associated factors among 12-year-old school children in Florianópolis, Brazil. Dent Traumatol. 2003;19(1):15-8.

11. Borssén E, Holm AK. Traumatic dental injuries in a cohort of 16-year-olds in northern Sweden. Endod Dent Traumatol. 1997;13(6):276-80.
12. Panzarini SR, Saad-Neto M, Sonoda C, Poi WR, Perri De Carvalho AC. Dental avulsion in young and adult patients in the region of Araçatuba. Rev Assoc Paul Cir Dent. 2003;57(1):2731.

13. Andreasen JO. External root resorption: its implication in dental traumatology paedodontics, periodontics, orthodontics and endodontics. Int Endod J. 1985;18(2):109-18.

14. Borssén E, Holm AK. Treatment of traumatic dental injuries in a cohort of 16-year-olds in northern Sweden. Endod Dent Traumatol. 2000;16(6):276-81.

15. Flores MT, Andersson L, Andreasen JO, Bakland LK, Malmgren B, Barnett F et al. Guideline for the management of traumatic dental injuries. I. Fractures and luxations of permanent teeth. Dent Traumatol. 2007;23(2):66-71.

16. Zuhal K, Semra OE, Huseyin K. Traumatic injuries of the permanent incisors in children in southern Turkey: a retrospective study. Dent Traumatol. 2005;21(1):20-5.

17. Agbelusi GA, Jeboda SO. Traumatic fracture of anterior teeth in 12-year old Nigerian children. Odontostomatol Trop. 2005;28(111):23-7.

18. Cortes MI, Marcenes W, Sheiham A. Prevalence and correlates of traumatic injuries to the permanent teeth of schoolchildren aged 9-14 years in Belo Horizonte, Brazil. Dent Traumatol. 2001;17(1):22-6.

19. Andreasen FM. Pulpal healing after luxation injuries and root fracture in the permanent dentition. Endod Dent Traumatol. 1989;5(3):11-3.

20. Cvek M, Cleaton-Jones P, Austin J, Lownie J, Kling M, Fatti P. Pulp revascularization in reimplanted immature monkey incisors - predictability and the effect of antibiotic systemic prophylaxis. Endod Dent Traumatol. 1990;6(4):157-69.

21. Trope M, Moshonov J, Nissan R, Buxt P, Yesilsoy C. Short $v s$. Long-term calcium hydroxide treatment of established inflammatory root resorption in replanted dog teeth. Endod Dent Traumatol. 1995;11(3):124-8.

22. Estrela C, Pesce HF. Chemical analysis of liberation of calcium and hydroxyl ions from calcium tissue in the dog. Part I. Braz Dent J. 1996;7(1):41-6. 